高速遠心成形法による高純度アルミナセラミックスの切削性能

\author{
田島 俊造, 山根八洲男, 黒木 英憲, 鳴瀧 則彦 \\ 広島大学工学部第一類, 7739 東広島市鏡山1-4-1.
}

\title{
Cutting Performance of High Purity Alumina Ceramic Tools formed by a High-speed Centrifugal Compaction Process
}

\author{
Shunzo Tashima, Yasuo Yamane, Hidenori Kuroki and Norihiko Narutaki \\ Cluster I, Fac. Eng. Hiroshima University, 1-4-1 Kagamiyama, Higashi-hiroshima 739.
}

Received December 21, 1994

\section{SYNOPSIS}

Using a high-speed centrifugal compaction process (centrifugal force : $1 \times 10^{4} \sim$ $2 \times 10^{4} \mathrm{G}$ ) developed by the authors, a slip prepared from alumina powder with a purity of $99.99 \%$ and an average particle size of $0.22 \mu \mathrm{m}$ was compacted, and sintered at $1230^{\circ} \mathrm{C}$ for 1.5 hours in the atmosphere. The sintered compact has superior mechanical properties, including a 3-point bending strength of $1330 \mathrm{MPa}$ and a Vickers hardness of 2100 .

The cutting performance of this high-strength alumina sintered compact was studied in this experiment. The results show that tools manufactured using the subject high-speed centrifugal compaction process have relatively high wear resistance and toughness as compared with commercially available high purity alumina ceramic tools.

\section{KEY WORDS}

alumina, high purity, centrifugal compaction, cutting tool, wear resistance.

\section{1 緒 言}

セラミックス泥槳を金型に装填後, 重力倍数 $1 \times$ $10^{4} \sim 2 \times 10^{4} \mathrm{G}$ 程度の高い遠心力を作用させて成形 する高速遠心成形法 ${ }^{1)}$ による高純度アルミナ超微物 の成形体は, $1220^{\circ} \mathrm{C}-2 \mathrm{~h}$ の低温焼成で相対密度 $99 \%$ 以上の烧成体が得られ, S E M 観察では結晶粒が 微細でボイドが認められず均質であり，優秀な機械 的性質を有する ${ }^{2}$.

従来, アルミナ焼成体は高温強度が高く，鉄と化 学的に反応し難いなど切削工具として好ましい性質 を有する反面, アルミナージルコニア焼成体など
に比べ勒性が低く，熱衝撃に弱いとされている ${ }^{3)}$. しかし，上記高速遠心成形法による焼成体は従来の アルミナに比べ高強度であり，そのようなアルミナ は高橋ら ${ }^{4}$ 5) が指摘しているように切削工具として 耐摩耗性，耐欠損性に優れる可能性がある.

また, 高橋ら ${ }^{45}$ (5アルミナセラミックスの高強 度化および用途应大を目的として, 高純度アルミナ を真空焼成後, H IP して平均粒径 $0.8 \mu \mathrm{m}, 3$ 点曲 げ強度 $1300 \mathrm{MPa}$ の焼成体を得て, その性質や切削 性能を検討している.しかし，H IP 処理を施す場合， 粒成長抑制のために $500 \mathrm{ppm}$ 程度の $\mathrm{MgO}$ を添加す 
ることが必要で, $1000 \mathrm{ppm} の \mathrm{MgO}$ 添加により高温 強度が低下するとの報告 ${ }^{6)}$ があり, その種の添加物 を要しないことも高速遠心成形法によるアルミナの 長所になる可能性がある.

そこで本実験では, 高純度アルミナ超微粉の高速 遠心成形体を $1230^{\circ} \mathrm{C}$ 低温で $1.5 \mathrm{~h}$ 大気焼成した高

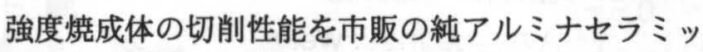
ク工具と比較して調查した.

\section{2 実験方法}

\section{1 使用材料及び成形焼成}

本実験で使用したアルミナ粉末（大明化学工業製 タイミクロンTM-DAR)は純度 $99.99 \%$, 平均粒径0.22 $\mu \mathrm{m}$ で, 非常に微細かつ高純度である.

分散処理の条件及び泥漿の特性を Table 1 に示す. 既報1 2. 7) とほとんど同様で, 分散材にはポリカル ボン酸アンモニウム(東亜合成化学製アロンA-6114) を，結合剤にはアクリルポリマー（東亜合成化学製 AS-7503)を用いた．泥漿の粘度はずり速度 $19.2 \mathrm{~s}^{-1}$ において $100 \sim 300 \mathrm{mPa} \cdot \mathrm{s}$ ( 分散処理温度 $12 \sim 15{ }^{\circ} \mathrm{C}$, 粘度測定温度 $20 \pm 0.5^{\circ} \mathrm{C}$ )であった.

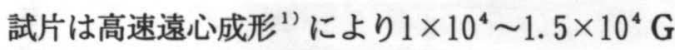
の遠心力で $16 \times 16 \mathrm{~mm}$ 角, 高さ $7 \mathrm{~mm}$ にアルミニウ 么合金製金型を使用して成形した. 成形体の水分量 は約 14 mass \%, 粒子充填率は約 62\%であった.

成形体は, 乾燥後大気炉により $500^{\circ} \mathrm{C} て ゙ 1 \mathrm{~h}$ 脱脂を 行い, $1230^{\circ} \mathrm{C} て ゙ 1.5 \mathrm{~h}$ 焼成した.

\section{2 工具形状及び材料特性}

焼成体は, IS0規格のSNGN120408 と同一形状(チャ ンファ形状: $0.18 \mathrm{~mm} \times 25^{\circ}$ )に研削加工し工具(以下, AC工具と略す) とした. 比較した工具は市販の純 アルミナ系セラミック工具(以下, AW 工具)である.

Table 1 Compositions and properties of slip.

\begin{tabular}{|l|l|}
\hline Slip concentration & 75 mass\% \\
\hline $\begin{array}{l}\text { Dispersion agent } \\
\text { (Poly-carboxylic ammonium) }\end{array}$ & 0.6 mass\% \\
\hline $\begin{array}{l}\text { Binder } \\
\text { (Acrylic polymer) }\end{array}$ & 0.1 mass\% \\
\hline Dispersion time & $16 \sim 48 \mathrm{~h}$ \\
\hline $\begin{array}{l}\text { Coefficient of viscosity } \\
\text { (Dispersion temperature) }\end{array}$ & $\begin{array}{c}100 \sim 300 \mathrm{mPa} \cdot \mathrm{s} \\
\left(12 \sim 15{ }^{\circ} \mathrm{C}\right)\end{array}$ \\
\hline
\end{tabular}

Table 2 Properties of ceramic samples.

\begin{tabular}{|c|c|c|}
\hline & AC & AW \\
\hline $\begin{array}{c}\text { 3-point bending } \\
\text { strength (MPa) }\end{array}$ & 1330 & $780 *$ \\
\hline $\begin{array}{c}\text { Vickers hardness } \\
\text { (by 49 N) }\end{array}$ & 2100 & 1650 \\
\hline $\begin{array}{c}\text { Fracture toughness } \\
(\mathrm{IF} \text { Method, by 196N) } \\
\left(\mathrm{MPa} / \mathrm{m}^{1 / 2}\right)\end{array}$ & 3.3 & 3.5 \\
\hline Density ( Mg/m³) & 3.95 & 3.94 \\
\hline Relative density (\%) & 99.0 & -- \\
\hline
\end{tabular}

(*\%: Manufacturers' data)

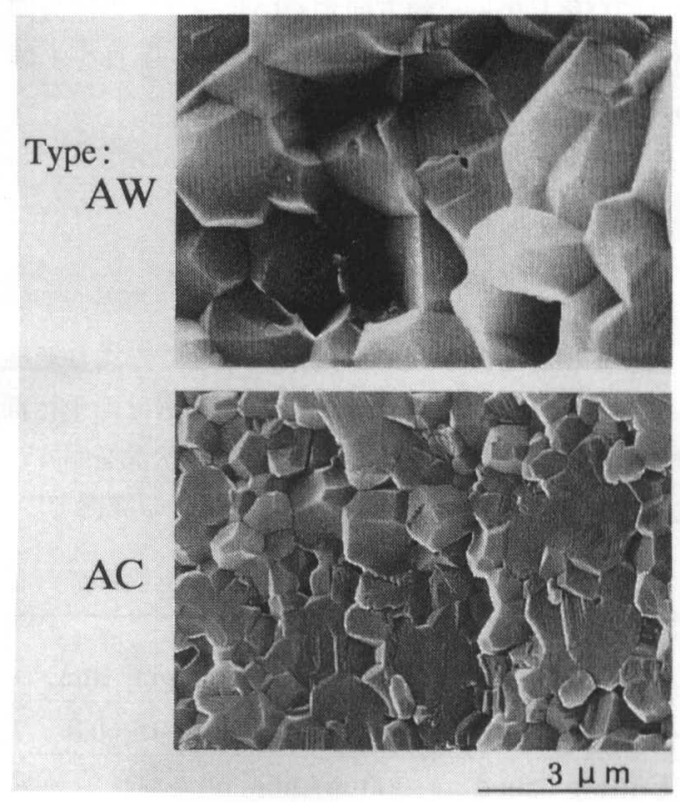

Photo. 1 Scanning electron micrographs of fracture surfaces.

各工具の特性を Table 2 に示す. なお, 曲げ強度 は 3 点曲げ(JIS R1601, スパン $30 \mathrm{~mm}$ )により, 破壊 勒性值は IF 法により荷重 196 N ( $20 \mathrm{~kg} \mathrm{f}$ ) で測定 した. 市販品の AW工具に比べ A C工具が， 3 点 曲げ強度は約 70\%, ビッカース硬度は約 30\%高い值 を示したが，破壊勒性值は同等であった。

各工具の破面のS E M 写真を Photo. 1 に示す.

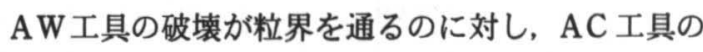
破壊は粒内を通って進展しており高強度を裏付けて いる. 破面写真から平均粒径を測定すると， AC工 具は約 $0.7 \mu \mathrm{m} て ゙$ 微細な組織であるが, $\mathrm{AW}$ 工具は 約 $2 \mu \mathrm{m}$ であった. 


\section{3 切削実験}

切削実験では工具の耐摩耗性と耐欠損性を調べた。 耐摩耗性試験は, FC 250普通鋳鉄の連続鋳造材 (FC 250-CC) 丸棒について乾式外径旋削を行い, 工具 の横逃げ面の摩耗幅を測定, 評価した. 工具の取付 角は $(-5,-5,5,5,15,15,0.8)$ である.

また耐欠損性試験は, マシニングセンタを用いた $\mathrm{S} 45 \mathrm{C}$ 炭素鋼角ブロックの正面フライス切削で行っ た. 試験は, 切削速度を一定 $(200 \mathrm{~m} / \mathrm{min})$ とし， 一定距離 $(480 \mathrm{~mm}$ ) 切削する毎に送りを順次高めて, 欠損するまでの最大送り量で耐欠損性を評価した. なお, 実験は各 3 回行い, 3 回の繰り返しで何れも 欠損した場合を切削不能と判断した. 使用したカッ 夕は呼び径 $100 \mathrm{~mm}$, 軸方向すくい角 $-5^{\circ}$, 半径方向 すくい角 -5 のダブルネガタイプで, 工具を 1 個 のみ取り付けて実験した.

それぞれの実験条件を, Table 3,4に示す.

\section{3 結 果}

\section{1 旋削による耐摩耗性試験}

Fig. 1 に FC250-CCの切削において, 送り速度 $0.39 \mathrm{~mm} / \mathrm{rev}$ とした場合の工具の横逃げ面平行部 摩耗幅及び前逃げ面境界摩耗幅の増加状況を示す. なお, 送り速度を0. 21 0.50 mm / rev の範囲で変

Table 3 Conditions of turning tests.

\begin{tabular}{|l|l|}
\hline Work & $\begin{array}{l}\text { FC 250 - C C } \\
\text { (Continuous - cast gray iron) }\end{array}$ \\
\hline Tool geometry & $-5,-5,5,5,15,15,0.8$ \\
\hline Cutting speed & $300 \mathrm{~m} / \mathrm{min}$ \\
\hline Depth of cut & $1.0 \mathrm{~mm}$ \\
\hline Feed rate & $0.21 \sim 0.50 \mathrm{~mm} / \mathrm{rev}$ \\
\hline Cutting fluid & Dry \\
\hline
\end{tabular}

Table 4 Conditions of face milling tests.

\begin{tabular}{|l|c|}
\hline Work & S $45 \mathrm{C}$ \\
\hline Work width & $80 \mathrm{~mm}$ \\
\hline Work length & $480 \mathrm{~mm}$ \\
\hline Cutting speed & $200 \mathrm{~m} / \mathrm{min}$ \\
\hline Depth of cut & $1.0 \mathrm{~mm}$ \\
\hline Feed rate & $\begin{array}{c}0.10 \sim 0.50 \\
\mathrm{~mm} / \text { tooth }\end{array}$ \\
\hline Cutting fluid & Dry \\
\hline
\end{tabular}

化させた場合, 同様の傾向であった. また, Fig. 1 の $5 \mathrm{~min}$ 切削時の工具写真を Photo. 2 に示す. これ らの結果によれば, 全体に $\mathrm{AW}$ 工具に比べ $\mathrm{AC}$ 工具

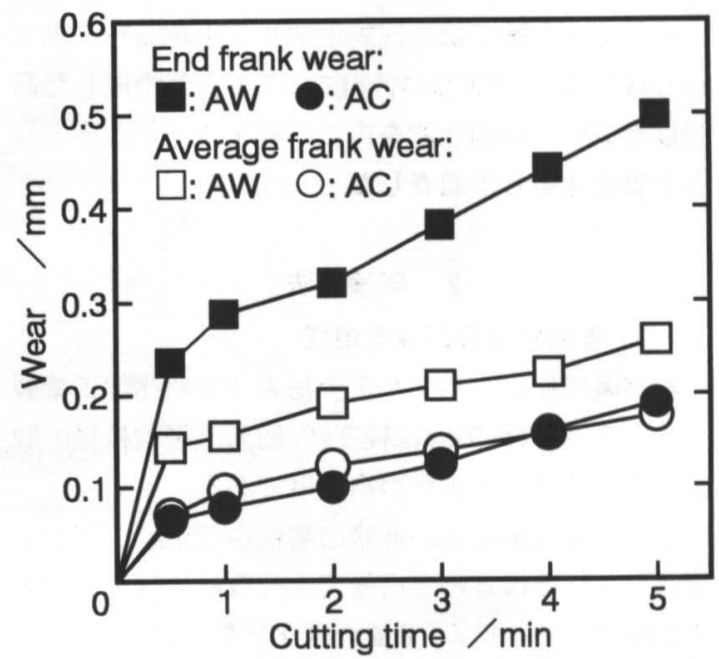

$(\mathrm{V}=300 \mathrm{~m} / \mathrm{min}, \mathrm{d}=1.0 \mathrm{~mm}, \mathrm{f}=0.39 \mathrm{~mm} / \mathrm{rev})$

Fig. 1 Wear progress curves of tools tested during turning $\mathrm{FC} 250-\mathrm{CC}$.

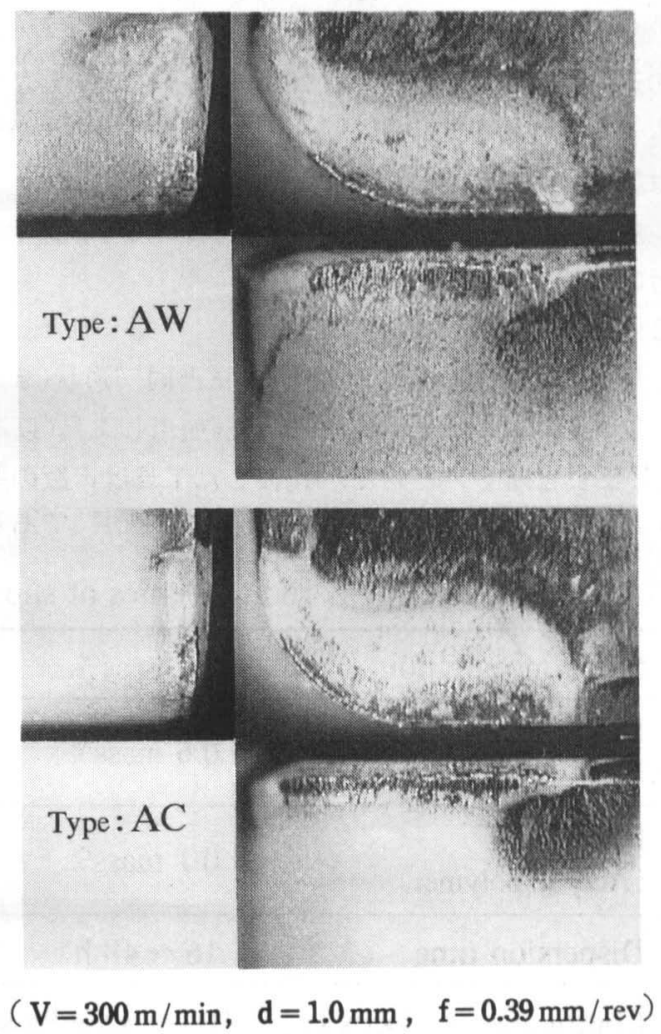

Photo.2 Wear pattern of tested tools (FC 250-CC, cutting time $=5 \mathrm{~min}$ ). 
の摩耗幅の方が小さく, 特に前逃げ面境界摩耗幅は $\mathrm{AC}$ 工具が AW 工具の約 $1 / 3$ であり, その差は歴然 としている.

\section{2 断続切削による耐欠損性試験}

Table 5 にS 45 C の正面フライス切削による耐欠 損性試験の結果を示す. また, 送り速度 $0.20 \mathrm{~mm} /$ tooth の場合の両工具の摩耗状況を Photo. 3 に示す.

AW 工具では $0.20 \mathrm{~mm} /$ toothの送りで境界部に チッピングあるいは欠損が見られるのに対し，AC 工具ではこれらが認められない.

これらの結果から，AC工具は市販の純アルミナ 系工具の $\mathrm{AW}$ よりも優れた耐欠損性を示すことが 分かる.

\section{4 考察}

実験結果から明らかなように, 高速遠心成形を利 用して成形, 焼成した AC 工具は, 耐摩耗性, 耐欠 損性の何れも市販の AW 工具に比べ優れていた. 一般に旋削加工における工具の耐摩耗性は, 溶着や 拡散などの現象が生じない場合は, 工具の硬さ（特 に高温硬さ）に左右され，断続切削における耐欠損 性は勒性及び耐熱亀裂性に左右されると考えられる. 本実験の AC 工具は Table 2 にも示しているよう に, 硬さ強度とも $\mathrm{AW}$ 工具に比へ優れており,これ らの特性が耐摩耗性の差として現れたものと考えら れる. また耐欠損性については, 勒性值は Table 2 のように, AC工具と AW 工具でほぼ同程度である が, $\mathrm{AC}$ 工具が焼成助剤を含まないことから, 高温 における強度低下は AC 工具の方が小さいと予想さ れる. 実際に, 本焼成体について結晶粒界の TEM 観察を行い, XEDS ( X- ray Energy Dispersive Spectroscopy）によりビーム径 $0.5 \mathrm{~nm}$ で組成分析 を行った結果 ${ }^{8)}$ では, 焼成体には粒界相が存在せず, 粒界不純物が検出されなかった. なお, 耐熱亀裂性 についても，AC 工具では工具すくい面に熱亀裂が 観察されても直ちに欠損に至ることは少なく, 亀裂 の進展速度が遅いことが推測される.

アルミナ系工具は, その開発以来, 耐欠損性の不 足が常に問題となり, 焼成助剤をはじめとして TiC やジルコニアの粉末あるいはウィスカなど様々な物 質の添加により勒性向上が図られてきた. しかし, 他成分の添加による改良は耐摩耗性を低下させる場 合が多いことから, 今日では耐欠損性があまり問題 とならない鋳鉄の旋削などに対して純アルミナ系工
Table 5 Results of face milling tests.

\begin{tabular}{|c|c|c|}
\hline $\begin{array}{l}\text { Feed rate } \\
(\mathrm{mm} / \text { tooth })\end{array}$ & AW & $\mathrm{AC}$ \\
\hline 0.10 & 000 & 000 \\
\hline 0.15 & 000 & 000 \\
\hline 0.20 & 000 & 000 \\
\hline 0.25 & $\times \times \times$ & 000 \\
\hline 0.30 & & 000 \\
\hline 0.35 & & 000 \\
\hline 0.40 & & $00 \times$ \\
\hline 0.45 & & $0 \times \times$ \\
\hline 0.50 & & $\times \times \times$ \\
\hline
\end{tabular}

( $O$ : No fracture , $x$ : Fracture)

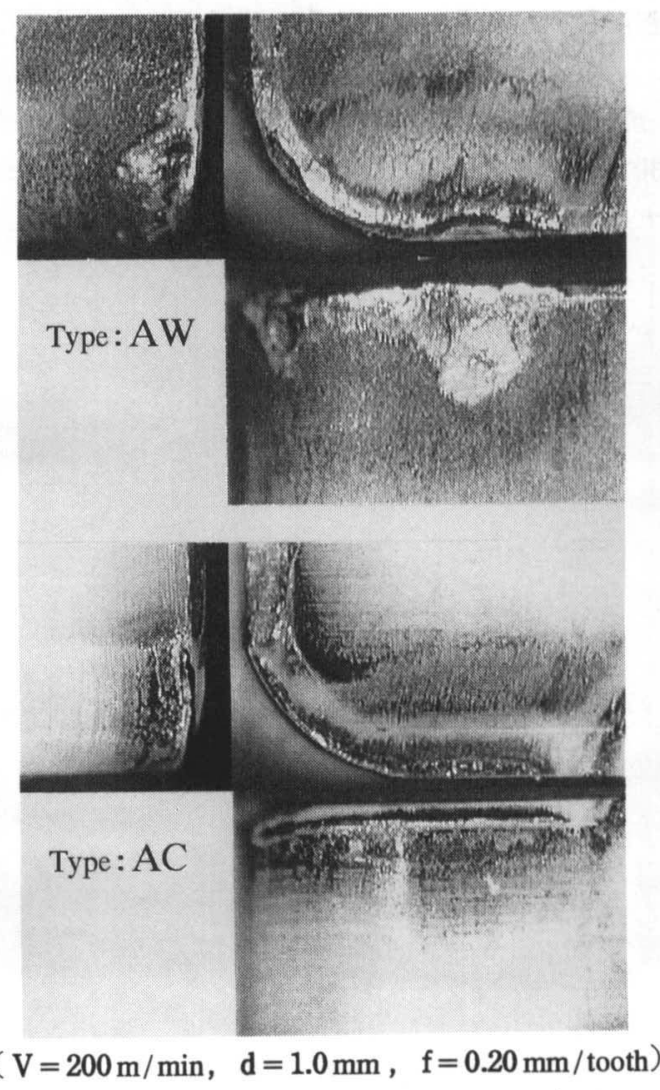

Photo.3 Wear pattern of tested tools (S $45 \mathrm{C}$, cutting time $=4 \mathrm{~min}$ ).

具が使用されている. その中で, 比較材として用い た純アルミナ系工具材料 AW は H IP 処理を行った り, 各種焼成助剂を添加するなどの方法を用いて作 製されている. 
それに対し，高速遠心成形法で比較的簡単に成形 した高純度アルミナが単なる大気中焼成により，切 削工具として使用に耐え得る優れた性質に達するの は極めて興味深いことであり，優れた機械的特性を 奏現する上での高速遠心成形法の高い可能性を示し ている.また，この材質発現のメカニズムを究明す ることは, 高温強度などとも関連して今後の重要課 題と考えられる.

\section{5 結 論}

純度 $99.99 \%$, 平均粒径 $0.22 \mu \mathrm{m}$ のアルミナ粉末 を高速遠心成形し，大気中で低温焼成して得た工具 と，市眅の純アルミナ系セラミック工具について 切削性能を比較した。耐摩耗性試験に FC 250 普通 鋳鉄（連続鋳造材），耐欠損性試験に S $45 \mathrm{C}$ 炭素鋼 を被削材として用いたところ，下記の結果が得られ た.

1）焼成助剤無添加の純アルミナを高速遠心成形後, $1230^{\circ} \mathrm{C}-1.5 \mathrm{~h}$ 大気焼成した焼成体は, 市販の純アル ミナ系セラミック工具以上の酎摩耗性を有する.
2）上記試作工具は，市販の純アルミナ系セラミック 工具に比へ，耐欠損性が高い.

\section{文献}

1）田島 俊造, 隅田 雅之, 黒木 英憲: 粉体および 粉末冾金, 39 (1992） 39.

2）田島 俊造，橋本 重昭，黑木 英囊：粉体および 粉末冶金, 41 (1994) 180 .

3）奥田 博, 平井 敏雄, 上垣外 修已: 構造材料セ ラミクス，オーム社(1987) 88.

4）高橋 俊行, 勝村 祐次, 鈴木 寿: 粉体および 粉末冶金, 40 (1993) 805.

5）高橋 伐行, 勝村 祐次, 鈴木 寿: 粉体および 粉末冶金, 41 （1994）33.

6) Y. Yoshizawa, T. Sakuma : Acta metall. mater., 40 (1992) 2943.

7) S. Tashima, H. Kuroki : Proc. Powd. Met. World Congress, Kyoto (1993) 883.

8）螣谷聡一郎, 小池淳一, 丸山公一, 田島俊造, 及川 洪: 日本金属学会講演概要, 1995春期, №. 272. 